\title{
Belphégor
}

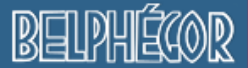

Littérature populaire et culture médiatique

11-1| 2013

Fantômas dans le siècle

\section{Antonutti, Isabelle. Cino Del Duca. De Tarzan à Nous Deux, itinéraire d'un patron de presse}

Rennes : Presses Universitaires de Rennes, 2012. 221 p.

ISBN 978-2-7535-2124-7

\section{Vittorio Frigerio}

\section{(2) OpenEdition}

Journals

Édition électronique

URL : http://journals.openedition.org/belphegor/223

DOI : 10.4000/belphegor.223

ISSN : 1499-7185

Éditeur

LPCM

Référence électronique

Vittorio Frigerio, «Antonutti, Isabelle. Cino Del Duca. De Tarzan à Nous Deux, itinéraire d'un patron de presse », Belphégor [En ligne], 11-1 | 2013, mis en ligne le 22 juin 2013, consulté le 22 septembre 2020 URL : http://journals.openedition.org/belphegor/223 ; DOI : https://doi.org/10.4000/belphegor.223

Ce document a été généré automatiquement le 22 septembre 2020.

\section{(c) (†) $९$}

Belphégor est mis à disposition selon les termes de la Licence Creative Commons Attribution - Pas d'Utilisation Commerciale - Pas de Modification 4.0 International. 


\section{Antonutti, Isabelle. Cino Del Duca. De Tarzan à Nous Deux, itinéraire d'un patron de presse}

Rennes : Presses Universitaires de Rennes, 2012. 221 p.

ISBN 978-2-7535-2124-7

Vittorio Frigerio

\section{RÉFÉRENCE}

Antonutti, Isabelle. Cino Del Duca. De Tarzan à Nous Deux, itinéraire d'un patron de presse. Rennes : Presses Universitaires de Rennes, 2012. 221 p. ISBN 978-2-7535-2124-7 
1 Avec cet ouvrage soigneusement documenté et qui se lit presque plus comme un roman d'aventures que comme une biographie, Isabelle Antonutti retrace la carrière d'un patron de presse d'un genre on ne peut plus particulier, selfmade-man à l'éducation parcellaire, militant socialiste en sa jeunesse, émigré en France sous le fascisme pour des raisons au moins aussi économiques que politiques, qui a crée certains des titres les plus connus et vendus de l'édition populaire du vingtième siècle des deux côtés du Mont Blanc. Cino Del Duca commence sa carrière dans l'édition en distribuant les publications d'autres maisons spécialisées dans les romans populaires, avant de donner naissance à des titres d'une longévité et d'une importance considérable dans l'histoire $\mathrm{du}$ fumetto italien, comme Il Monello et

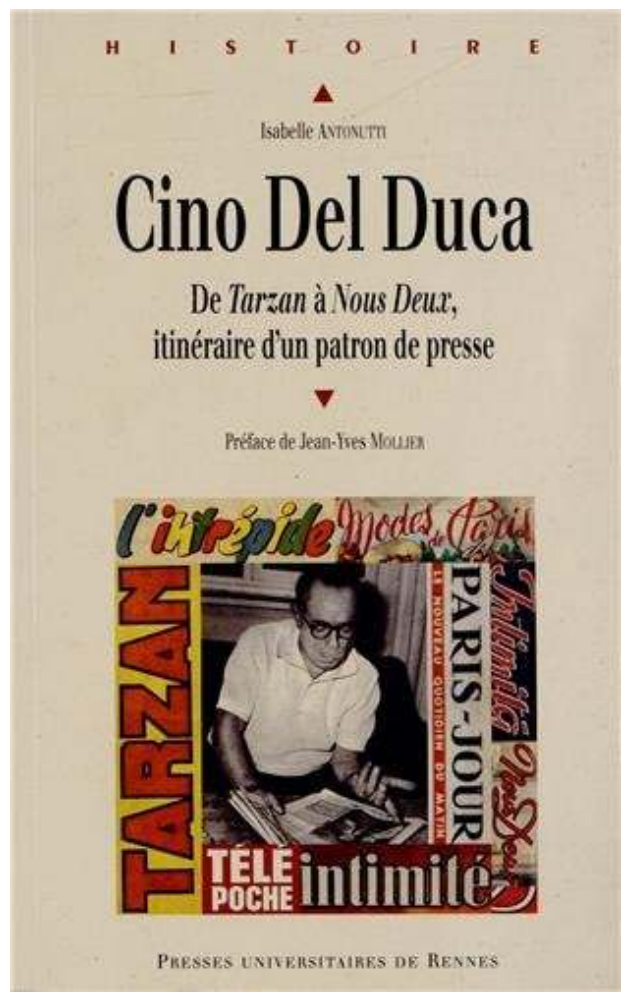
L'Intrepido. En France, à côté des productions de cet autre immigré, Paul Winkler, ses journaux, dont Hurrah! et L'Aventureux, véhicules de la bande dessinée d'aventures américaine, ont été à l'origine de l'âge d'or de la BD.

2 Isabelle Antonutti reconstruit avec une abondance louable de détails aussi pertinents que fascinants le trajet de cet homme d'affaires improbable, qui sonde les goûts du public en interrogeant les ménagères dans la rue et les enfants à la sortie des écoles, et parvient à se tailler une place de premier plan dans le panorama de l'édition populaire européenne. Un brin hâbleur à l'occasion, amateur de belles voitures et de belles femmes, Cino Del Duca , travailleur infatigable et grand preneur de risques, revit à travers ces pages avec tout l'éclat des illustrations de ses imprimés les plus célèbres, avec ses nombreux mérites, mais aussi avec ses limites claires ; avec sa générosité et sa sympathie humaine, et avec ses ambiguïtés, ses louvoiements d'homme d'affaires toujours en quête d'une bonne occasion dans un marché européen affamé de productions fictionnelles passionnantes et déstabilisé par les tensions politiques qui conduiront à la guerre.

Pendant la guerre elle-même, le parcours de l'éditeur - qui parvient encore à publier, cas rarissime, en zone sud comme en zone nord - est pour le moins problématique. Isabelle Antonutti reconstruit avec beaucoup de rigueur les déplacements nombreux de Cino Del Duca pendant le conflit et déconstruit avec application ses narrations autohagiographiques. Elle retrouve ainsi un personnage complexe, doté d'un entregent peu commun, qui mêle connaissances et fréquentations provenant d'horizons politiques incompatibles et parvient, malgré les doutes très légitimes de sa biographe, à se faire octroyer à la fin de la guerre des attestations certifiant de ses qualités de résistant. Quoi qu'il en soit, qu'il ait été pendant cette période un agent double ou plus simplement un mordu de la presse, disposé à tout faire pour poursuivre son métier, Del Duca est de 
nouveau bientôt sur la brèche. Il crée alors Nous Deux, le journal des romans-photo, dont le succès ne se démentira jamais.

Devenu le roi incontesté de la presse du cœur, avec quantité de revues à son actif tout aussi bien en France qu'en Italie, Del Duca songe à se diversifier et à chercher une forme de consécration culturelle, alors même que l'église et le parti communiste critiquent conjointement les effets néfastes, moralement et idéologiquement parlant, que la lecture de ses revues aurait sur l'esprit des femmes du peuple. Dès les années cinquante, cela l'amènera à se lancer dans la production cinématographique (c'est grâce à lui, notamment, que sortiront des classiques comme " Touchez pas au grisbi » et "Accattone ») et dans l'édition littéraire (avec un succès nettement moindre).

5 Une des constantes du parcours éditorial de Cino Del Duca semble avoir été la désorganisation. Pour le dire avec les mots de l'auteure: "La recherche de la rentabilité ne laisse aucune place à la cohérence » (139). En dépit de cela, la bataille continuelle des époux Del Duca (car il ne faut pas oublier sa femme Simone, figure importante de la maison) pour acquérir un minimum de reconnaissance symbolique, contre le « lourd discrédit culturel et professionnel » (143) qui continue de peser sur la presse populaire, rythme le parcours d'une aventure éditoriale qui a laissé des traces profondes dans l'imaginaire français.

6 Si un des buts d'une bonne biographie est celui de donner au lecteur l'envie d'avoir connu personnellement son sujet, il est ici pleinement atteint. Arrivé au bout du volume, il est difficile qu'on ne regrette pas de ne pas avoir eu l'occasion de croiser le chemin de ce monstre sacré de l'édition - que les délateurs de son pays natal indiquaient a la police fasciste comme évidemment incapable de diriger une maison d'édition du fait de sa scolarité très limitée -, doué d'une ténacité à toute épreuve qui, à elle seule, compense largement la liste pourtant longue de ses carences.

Qu'était donc Del Duca? Un «self-made-man » à l'américaine ou un "parvenu » à la française? Sans doute un peu des deux. Le mérite de cet ouvrage est surtout de mettre en lumière les multiples facettes du personnage sans céder à la fascination ou à l'évocation mélancolique, et de reconstruire à travers lui toute une époque et des usages de lecture naguère encore universels, maintenant déjà presque désuets. Isabelle Antonutti signe ici un livre important pour l'histoire de la presse européenne et pour celle du développement de la culture médiatique.

\section{AUTEURS}

\section{VITTORIO FRIGERIO}

Dalhousie University 